\title{
Numerical Study of Single Well Vapor Extraction Process
}

\author{
Milad Rahnema, ${ }_{1}^{1}$ Hamed Rahnema, ${ }^{2}$ Marcia D. Mcmillan, ${ }^{3}$ \\ Ali Reza Edrisi, ${ }^{4}$ and Hamid Rahnema ${ }^{3}$ \\ ${ }^{1}$ National Iranian Oil Company, Tehran, Iran \\ ${ }^{2}$ Islamic Azad University of Quchan, Quchan, Iran \\ ${ }^{3}$ New Mexico Tech, Socorro, NM, USA \\ ${ }^{4}$ Nicholls State University, Thibodaux, LA, USA \\ Correspondence should be addressed to Milad Rahnema; milad.rahnema@gmail.com
}

Received 20 April 2016; Revised 4 September 2016; Accepted 3 October 2016

Academic Editor: S. Ali Mousavi-Dehghani

Copyright (C) 2016 Milad Rahnema et al. This is an open access article distributed under the Creative Commons Attribution License, which permits unrestricted use, distribution, and reproduction in any medium, provided the original work is properly cited.

Vapor extraction (Vapex) is an emerging technology to produce heavy oil and bitumen from subsurface formations. Single well (SW) Vapex technique uses the same concept of Vapex process but only with one horizontal well. In this process solvent is injected from the toe of the horizontal well with oil production at the heel section. The main advantage of SW-Vapex process lies in the economic saving and applicability in problematic reservoirs, where drilling of two horizontal wells is impractical. The performance of SW-Vapex seems to be comparable with dual horizontal Vapex process using proper optimization schemes. This study is grouped into two sections: (i) a screening study of early time operating performance of SW-Vapex and (ii) a sensitivity analysis of the effect of the reservoir and well completion parameters. Simulation results show that solvent injection rate can be optimized to improve oil production rate. Higher injection rates may not necessarily lead to increase in production. This study confirms that SW-Vapex process is very ineffective in reservoirs with high oil viscosity (more than 1,500 cp) and thin formations (less than $10 \mathrm{~m}$ ).

\section{Introduction}

Heavy oil and bitumen reserves represent a considerable portion of worldwide energy resources. It is estimated that these reservoirs contain six trillion barrels of STOOIP which is much higher than the total conventional oil reservoirs. Significant consumption of light oil reserves and therefore their dramatic decline encourage more interest in the exploitation of highly viscous oil and bitumen for future energy demands. For the optimum conditions, the primary recovery of these reservoirs would not exceed 10 percent of the STOOIP. Most of these heavy oil and bitumen deposits are located in Canada, Venezuela, China, and Indonesia. Production from these reservoirs is challenging and technically difficult. Recently, vapor extraction process (Vapex) is introduced as an attractive method for such viscous oil reservoirs $[1,2]$.

In a reservoir where oil is very viscous and cannot flow in reservoir condition, adding of vaporized hydrocarbon solvents (HCS) can drastically reduce oil viscosity. This concept is the fundamental of Vapex. In a conventional Vapex approach, the solvent is injected into a horizontal well located directly above a horizontal producer. As the solvent diffuses and dissolves in the bulk of the reservoir, a chamber of solvent vapor grows around the injection well and helps the gravity drainage of diluted oil toward the production well, from where it is pumped out to the surface.

Depending on reservoir condition, several other well configurations are also possible. Butler and Jiang [3] conducted a series of experiments to study the effect of different well configurations on the performance of the Vapex in a homogeneous laboratory model. They found that the performance of process with producer and injector located in the same depth with horizontal separation was as well as conventional Vapex well configuration. Proper selection of well configuration is desirable to control the initial displacement and the profile of vapor chamber in the formation. Yazdani and Maini [4-6] carried out an extensive experimental study using 2D laboratory model to investigate the effect of porous media permeability and effective drainage height on the performance of the Vapex process. Later, Rezaei et al. [7] 
showed that, unlike SAGD process, the oil-wet condition of the formation positively impacts the oil production rate. To improve the economic viability of Vapex process, Torabi et al. [8-10] suggested injecting the noncondensable gases like $\mathrm{CO}_{2}$ with a hydrocarbon solvent. Using numerical simulation they found out that $\mathrm{CH}_{4}$ or $\mathrm{CO}_{2}$ coinjection is a viable option and results in equal or greater recovery factors in most cases.

In single well (SW) Vapex a horizontal well is completed such that it plays the role of both injector and producer. The similar well configuration has been studied for SAGD process [11-13]. In this well setting, the performance of horizontal well section plays a major role in the overall success of the process. A significant body of work has been done on injected fluid distribution along the horizontal section [14-17]. For single well Vapex process, vaporized solvent is injected at the toe of the well, while diluted oil is produced at the heel of the well. Since the vapor chamber grows over a majority of the reservoir, it is expected that only early time production for SW-Vapex varies from conventional approach, and the late-time production results are similar. The main advantages of SW-Vapex are cost saving and its applicability in problematic reservoirs where drilling of two horizontal wells is impractical. However, the process requires more comprehensive study to evaluate its feasibility.

Vapex process has been extensively studied using laboratory experiments. The main limitation is the low oil production compared to other thermal recovery processes $[1,3,18,19]$. Viscosity reduction mechanism in Vapex is based on mass diffusion process which is lower than thermal diffusion by orders of magnitudes which cause significant lower oil dilation and consequently lower oil production rate [20]. Also limited oil-solvent contact area causes another issue that makes this process very sensitive to the formation heterogeneities [21-24].

One of the alternative methods is to heat up the injected solvent to take advantage of both thermal and mass diffusion for oil viscosity reduction (N-Solv) [25-27]. Recent studies in this area show that N-Solv can significantly improve the low production rate, in some cases, comparable to SAGD process. However, these estimations are all based on laboratory experiments, and no field applications are available to support the proficiency of N-Solv in steam-based recovery method. One of the main challenges of N-Solv is the low heat capacity of injected solvent compared to steam.

Recently, solvent-assisted SAGD process showed promising potential for efficient heavy oil recovery. In this process, steam is used as the main heat carrier and the coinjected solvent is the axillary factor in the further reduction of oil viscosity. Nasr et al. [28-30] proposed this method and using experimental tools they showed that, compared to conventional SAGD, this ES-SAGD (expanding solvent steam assisted gravity drainage) can improve oil production rate with lower steam oil ratio (SOR) and lower energy and water requirements. Proper well constraints (i.e., pressure, temperature, and rates), solvent composition, and steamsolvent ratios are among the important factors impacting the outcome of the ES-SAGD [31-37].

Application of one single well in the Vapex process has not been addressed in the literature. However, Elliot and
Kovscek [38] have carried out a simulation study on the application of single horizontal well in SAGD process in heavy oil reservoirs. They showed that preheating the near wellbore area improves the performance of single well SAGD process by creating an initial steam chamber in surrounding area of the well. Later, Akin and Bagci [39] performed an experimental study to investigate the efficiency of the single well SAGD and optimized the startup procedure of the production. Also, the experimental results were confirmed by a simulation study. They emphasized that the project economics can be highly influenced by the early production response and showed that the principal mechanism in single well SAGD is steam formation and growth.

Although the Vapex process is accomplished by mass transfer and the dominant mechanism in SAGD is heat transfer, the central idea of both processes is the growth of an egglike vapor (steam or hydrocarbon solvent) chamber within the reservoir. Therefore, in this work, the same methodology was used to move toward the simulation of SW-Vapex. In the present study, a simulation model was developed to investigate the feasibility of single well Vapex. The approach includes, first, optimizing the early time performance of the SW-Vapex and, second, performing a sensitivity analysis to study the effect of the reservoir and well completion parameters on the process.

\section{Simulation Model}

2.1. Reservoir Model. The reservoir model selected for simulation of SW-Vapex process is a homogeneous, anisotropic, three-dimensional system consisting of 5,568 grid blocks. The grid system is Cartesian with local grid refinement as detailed in Figures 1 and 2. The reservoir is $1400 \mathrm{~m}$ in $X$-direction, $80 \mathrm{~m}$ in $Y$-direction, and $19.6 \mathrm{~m}$ in $Z$-direction. With the average porosity of $33 \%$ and connate water saturation of $15 \%$, the total reservoir hydrocarbon pore volume is $615,754 \mathrm{~m}^{3}$. The absolute permeability is $1,500 \mathrm{md}$ in the $X$ and $Y$ directions and $800 \mathrm{md}$ in the vertical direction. Initially, the average reservoir pressure is $1.1 \mathrm{Mpa}$, the pressure distribution is hydrostatic, and the reservoir temperature is $20^{\circ} \mathrm{C}$. The reservoir and fluid properties are listed in Table 1 . The values of these properties were selected based on a typical Alberta reservoir.

The single horizontal well is simulated using discretized wellbore model [40] (released with CMG version 98.01) that accurately represents fluid and heat transfer in the well. The well is divided into two parts whose lengths are equal, and they coincide end to end. It is assumed that a packer will isolate a $160 \mathrm{~m}$ distance between two wells. This configuration provides a flexible model to study different well completion and operating procedure. The properties of crude oil used in simulations were obtained from PVT lab tests. To simplify the analysis and reduce simulation run time, the lumping method was considered in developing the fluid model, and the number of components was decreased to four pseudocomponents. The initial oil viscosity at reservoir condition is $8,770 \mathrm{cp}$ and by raising the oil temperature to 


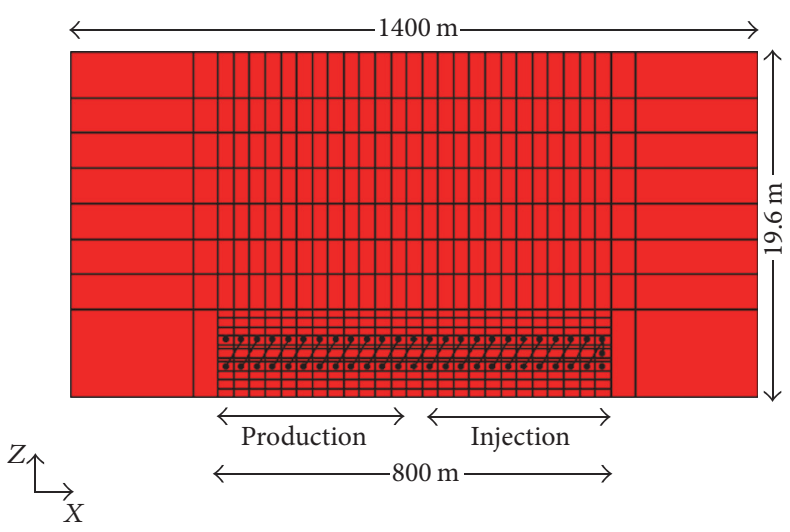

Figure 1: $X-Z$ cross section of the simulation model.

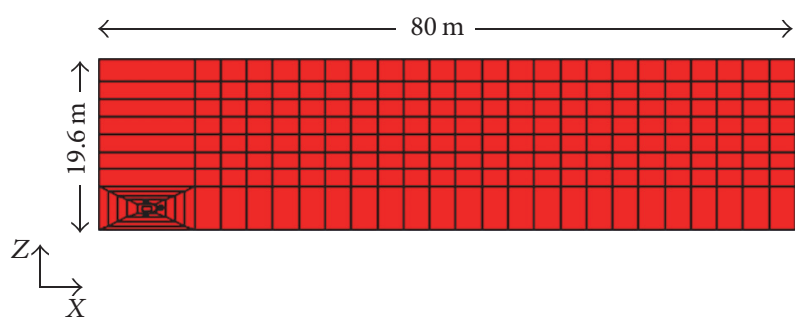

FiguRE 2: $Y-Z$ cross section of the simulation model, perpendicular to the horizontal well.

TABLE 1: Properties of the simulation model.

\begin{tabular}{lc}
\hline Property & Value \\
\hline Grid type & Cartesian \\
Length in X-direction & $1400 \mathrm{~m}$ \\
Length in $Y$-direction & $80 \mathrm{~m}$ \\
Length in Z-direction & $19.6 \mathrm{~m}$ \\
Number of grid cells & 5,568 \\
Average porosity & 0.33 \\
Horizontal permeability & $1500 \mathrm{md}$ \\
Vertical permeability & $750 \mathrm{md}$ \\
Number of components & 4 \\
Temperature & $20^{\circ} \mathrm{C}$ \\
Connate water saturation & 0.15 \\
Initial pressure & $1.1 \mathrm{MPa}$ \\
Initial oil viscosity @ 20 $0^{\circ} \mathrm{C}$ & $8770 \mathrm{mPa} \cdot \mathrm{s}$ \\
Solvent composition & $0.7 \mathrm{C} 3+0.3 \mathrm{C} 1$ \\
Well length & $800 \mathrm{~m}$ \\
Total hydrocarbon pore volume & $615,754 \mathrm{~m}{ }^{3}$ \\
\hline
\end{tabular}

$120^{\circ} \mathrm{C}$ the viscosity will reduce to $136 \mathrm{cp}$ as shown in Figure 3. The relative permeability data are given in Figures 4 and 5 .

2.2. Solvent Injection Criteria. The criterion that should be considered in selecting the solvent composition is that it should be at or near to its saturation point or in the case of solvent mixture near its dew point. This decisive factor should be met to avoid any liquefaction of the solvent before

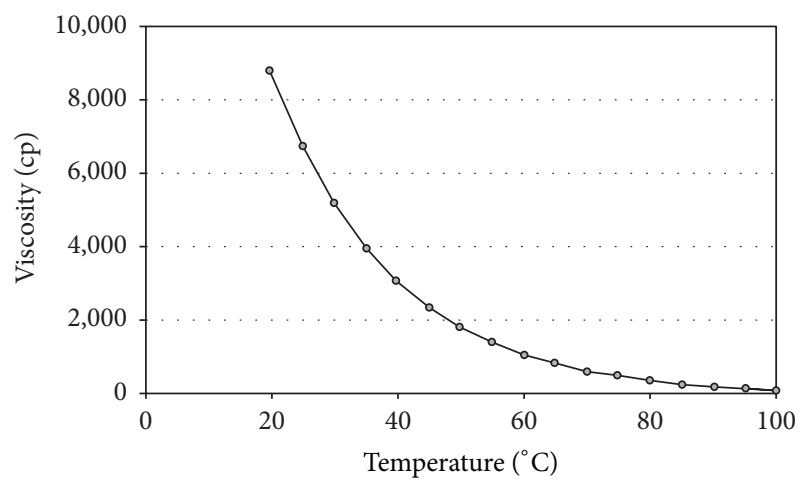

FIGURE 3: Oil viscosity versus temperature.

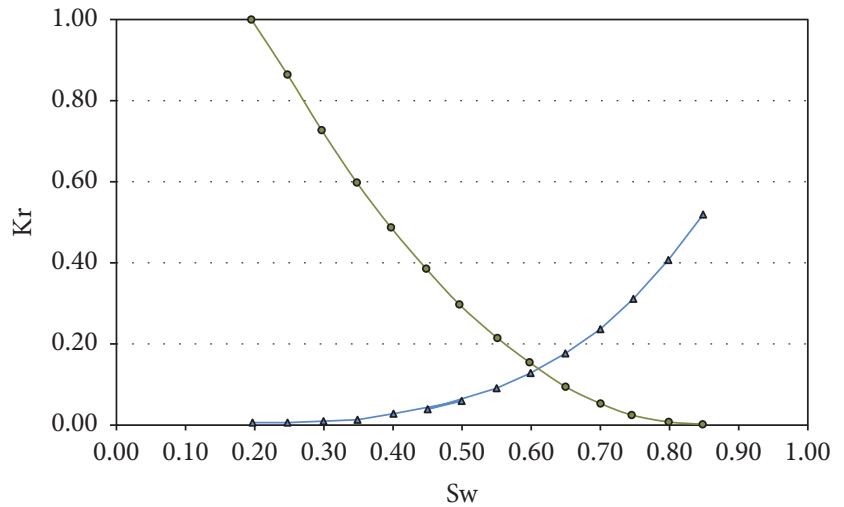

$\triangle$ Krw versus $S w$

$\rightarrow$ Kro versus $S w$

FIGURE 4: Oil-water relative permeability curve.

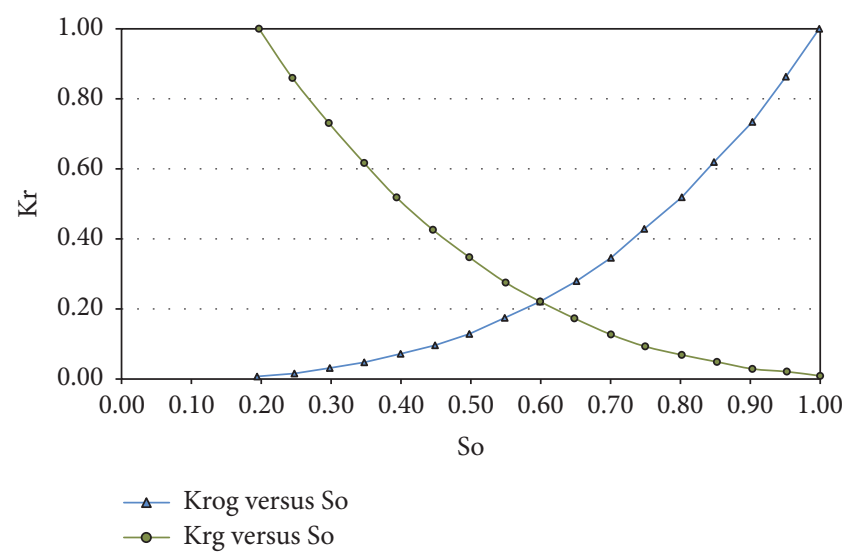

FIGURE 5: Gas-oil relative permeability curve.

it dissolves into heavy oil since this may cause higher solvent consumption, which results in higher oil production cost [4145]. Since the vapor pressure of typical solvents (propane or butane) is very low at the specified reservoir conditions, liquefaction of the solvent in the high-pressure reservoir is inevitable. To overcome this difficulty, the solvent should be 


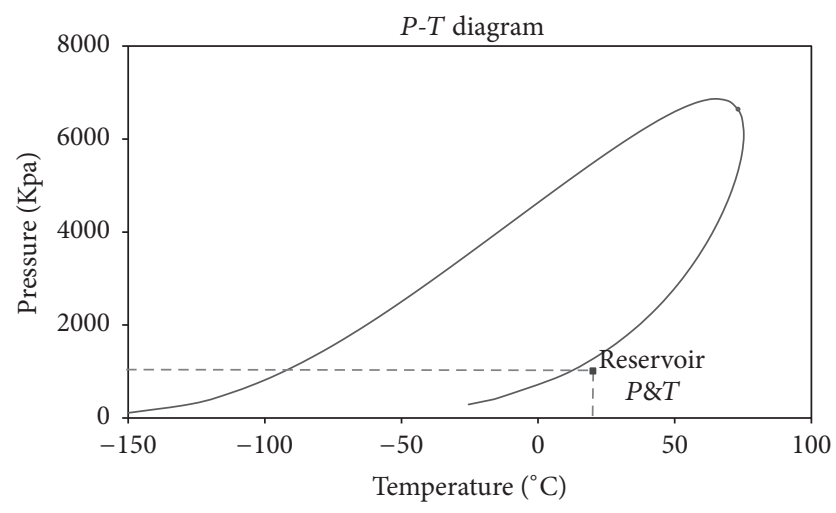

Figure 6: Phase diagram of injected solvent system with respect to reservoir temperature and pressure.

mixed with a suitable noncondensable gas such as methane to reach the dew point state under reservoir conditions. Different solvent mixtures were tested to find the best composition which meets the criterion above. Constructed phase envelope in WinProp module (CMG software) for a mixture of methane and propane indicates that a composition consists of $30 \%$ methane and $70 \%$ propane by mole fraction complying with this request. According to Figure 6, any change in the composition of the proposed mixture causes the injection operation condition to deviate from solvent saturation state and fall either in the two-phase or the superheated region. If the operation conditions fall within the $P-T$ diagram, the liquid solvent will be injected into the reservoir which as described before is undesirable.

\section{Results}

3.1. Early Time Performance. Vapor extraction is a slow process which is governed by mass diffusion, and therefore optimization schemes should be implemented to facilitate the process at the early time. Increasing of the gas-oil contact area at the early period of production should be considered to enhance the whole process by accelerating vapor chamber development. Thermal recovery methods especially steam injection can be used as an efficient alternative for this goal. For uniform heating of the near wellbore area and reducing the oil viscosity, the total length of the horizontal well can be used for steaming. In this way, an initial cavity is formed in the reservoir which increases the oil-solvent mass transfer area and therefore enhances oil dilution. To investigate the importance of initial thermal treatment and choose the appropriate heating method, different scenarios were considered with operation conditions summarized in Table 2.

The first scenario assumes thorough Vapex process from the beginning which can provide a reference case for comparison of the performance of other preheating strategies. In second case steam was injected at the toe of the horizontal well and simultaneously diluted oil is produced at the heel. The steam injection schedule which took 180 days was then followed by continuous solvent injection. The third and

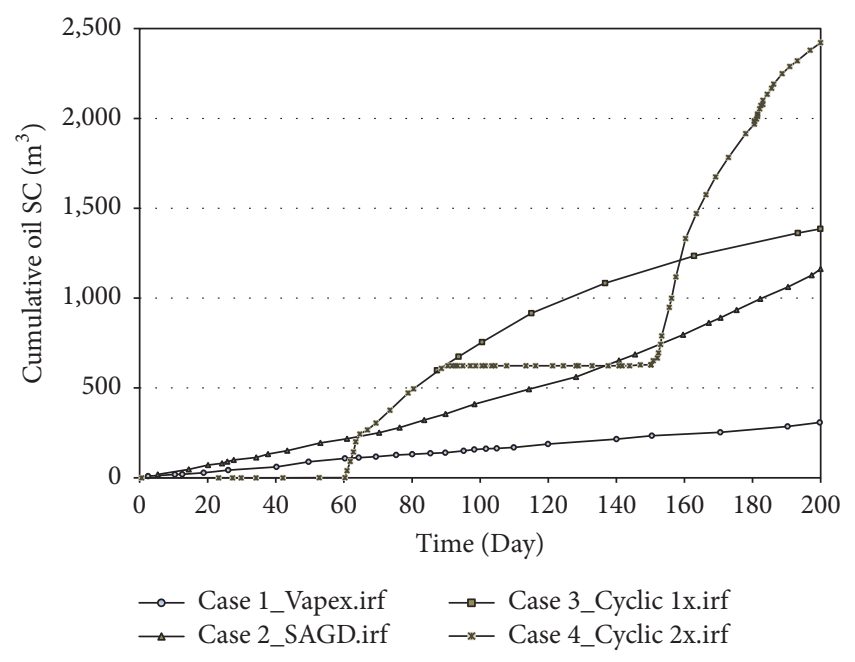

Figure 7: Cumulative oil production for different early time preheating scenarios during the first 180 days. Cyclic steam injection with two periods of injection/production leads to highest oil production (voidage in the reservoir).

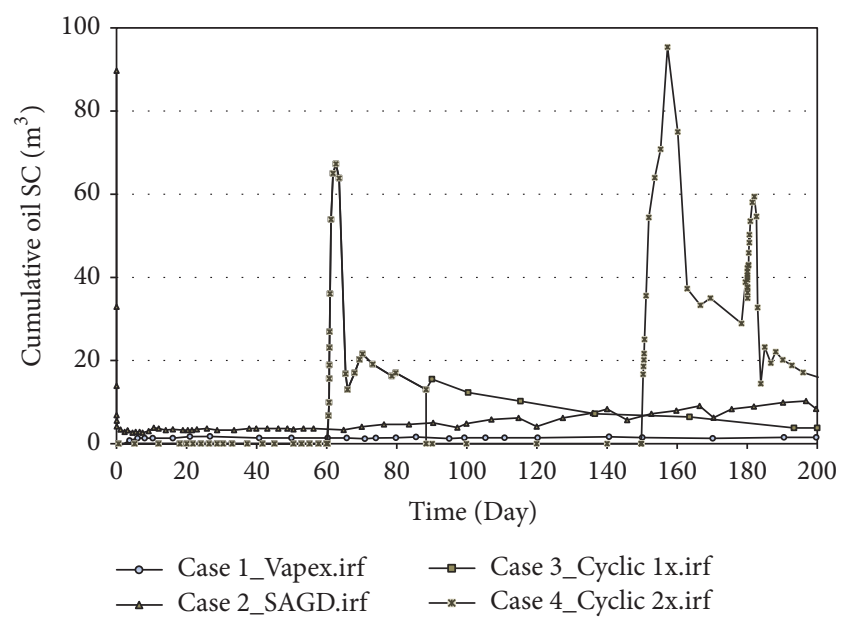

FIGURE 8: Oil production rate for different early time preheating scenarios during the first 180 days.

fourth cases include cyclic steam injection with different soak and production periods. In case 2 , steam is continuously injected from the toe of the horizontal well. Low injectivity was one of the main issues for this preheating method. To improve the injectivity problem, steam was injected in a cyclic way. In case 3 , the process starts with 20 days of steam injection and a soaking period of 40 days, then followed by 70 days of production (no steam injection). In case 4 , steaming, soaking, and production sequence is repeated twice then followed by Vapex process. The oil production profiles are illustrated in Figures 7 and 8. It can be seen that the cyclic steam injection with two periods of injection and production leads to higher recovery. Cyclic steaming (case 3 and 4) showed higher efficiency for initial preheating strategy compared to other methods. 
TABLE 2: Operation condition of early time scenarios.

\begin{tabular}{|c|c|c|}
\hline Case & Injection rate $\left(\mathrm{CWE} \mathrm{m}^{3}\right.$ /day) & Description \\
\hline Vapex & $2000\left(\mathrm{~m}^{3} / \text { day }\right)^{*}$ & Vapex from the beginning \\
\hline SAGD & 300 & SAGD for 180 days, followed by Vapex \\
\hline Cyclic 1x & 300 & 20 days of injection, 70 days of production, followed by Vapex \\
\hline Cyclic $2 \mathrm{x}$ & 300 & 20 days of injection, 70 days of production for 2 times, followed by Vapex \\
\hline
\end{tabular}

${ }^{*}$ Hydrocarbon solvent injection rate.

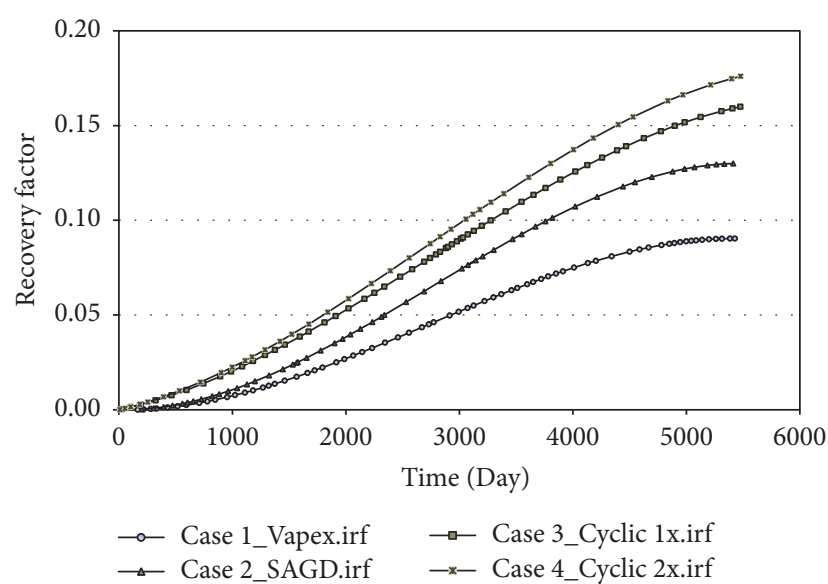

Figure 9: Effect of early time scenarios on the performance of SWVapex, after 15 years.

It should be mentioned that in case 1, the solvent is injected with operating pressure which is slightly higher than the average reservoir pressure. The gas breakthrough will happen after a while by immediate establishment of a short circuit between injection and production part of the horizontal well. The breakthrough time depends on oil mobility and the distance between well sections. Since the vaporized solvent remains in contact with a small portion of the reservoir, the efficiency of the process drastically reduces, and vapor chamber development is quite slow. Increasing the separation between the well sections does not improve the recovery, but it just delays the gas breakthrough time. In the following cases, it is attempted to maximize the initial contact area between the solvent and fresh heavy oil by creating a proper voidage in the reservoir.

Figure 9 indicates the effect of early time strategy on the ultimate oil recovery after 15 years. According to this figure, the cyclic steam injection can be considered as an important option for accelerating the process. Figure 10 displays the temperature profile after a cyclic steaming period which has provided uniform heating along the whole length of the horizontal well as well as a proper initial cavity in the reservoir. Figures 11 and 12 show the vertical view of the oil saturation and the viscosity distribution in the reservoir after 2,500 days according to which vapor chamber has been completely developed. As oil is diluted, it drains toward the producer. These figures obviously clarify that, like conventional Vapex process, SW-Vapex relies on vapor chamber development in the reservoir, and the same mechanism is applied.

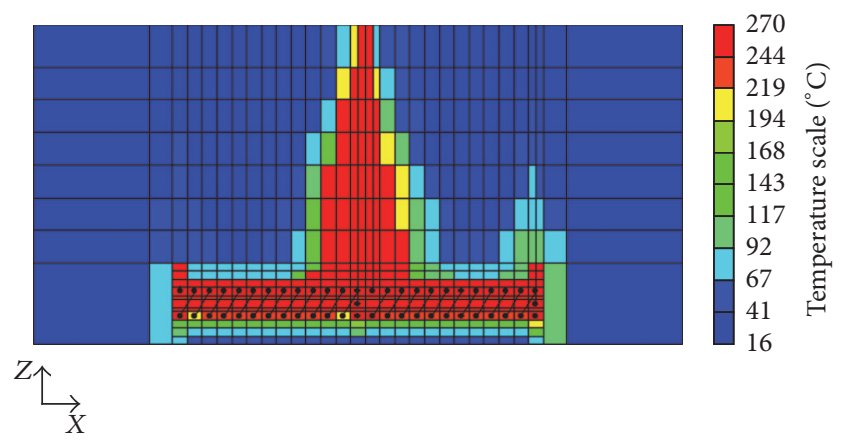

FIgURE 10: Temperature profile after 180 days, cyclic steam injection $2 \mathrm{x}$.

3.2. Sensitivity Study. Here, a series of sensitivity studies has been carried out to investigate the effect of operating conditions and reservoir parameters on the performance of SW-Vapex. Solvent injection rate, the presence of a small gas cap, reservoir thickness, and permeability anisotropy were considered for sensitivity study. All cases are started after 180 days of initial cyclic steam injection. The results are compared with the reference case whose properties are listed in Table 1. Figures 13 and 14 present the cumulative oil production for all sensitivity cases. The discussion of the results of each study is as follows.

Solvent Injection Rate. Solvent was injected with an average rate of $2,000 \mathrm{~m}^{3} /$ day. To investigate the effect of solvent injection rate, two other models were developed by increasing the gas injection rate to 3,500 and $4,500 \mathrm{~m}^{3} /$ day. Figure 13 shows that increasing the solvent injection rate could raise the oil recovery to some extent, and the amount of oil recovery enhancement is not significant after an optimum gas injection rate. This optimum value depends on the preheating method as well as the reservoir and fluid properties. Even the capillary pressure can intensify the effect of gas injection rate by dispersion phenomenon which has been recently addressed in the literature [14, 24, 46-53]. Mass transfer and gravity drainage are the dominant mechanisms in Vapex process which act side by side. As injected solvent diffuses into heavy oil, the viscosity reduces and oil drains toward the production section by gravity acceleration. Therefore, the injection rate should be adjusted in such a way that a balance between these two mechanisms is achieved. This injection rate corresponds to the optimum value at which the solvent to oil ratio hits the minimum. Extra injected solvent passes through the reservoir without participating in oil dilution process. 


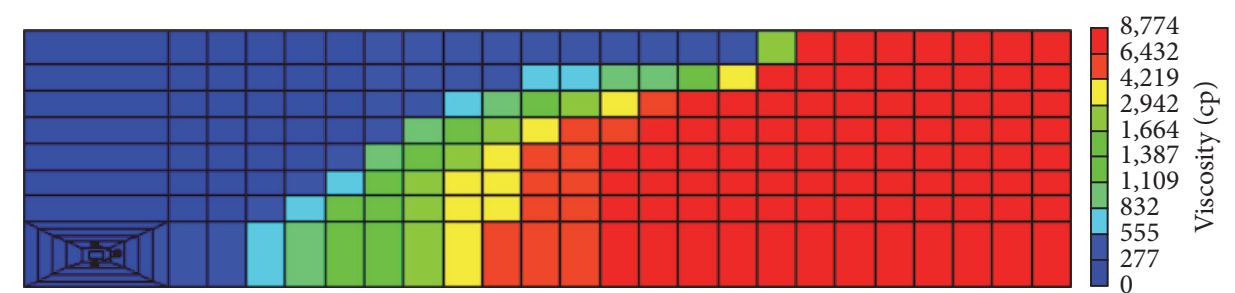

$\underset{\mathrm{Y}}{\stackrel{\mathrm{Y}}{\longrightarrow}}$

FIGURE 11: Vertical view of viscosity profile after 2,500 days; layer number in I direction: 24 .

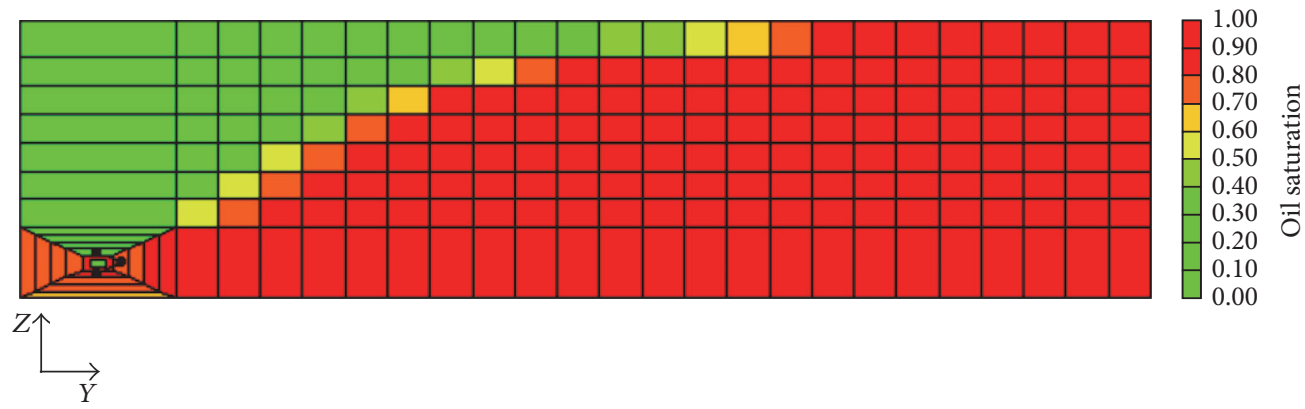

FIGURE 12: Vertical view of saturation profile after 2500 days; layer number in I direction: 24.

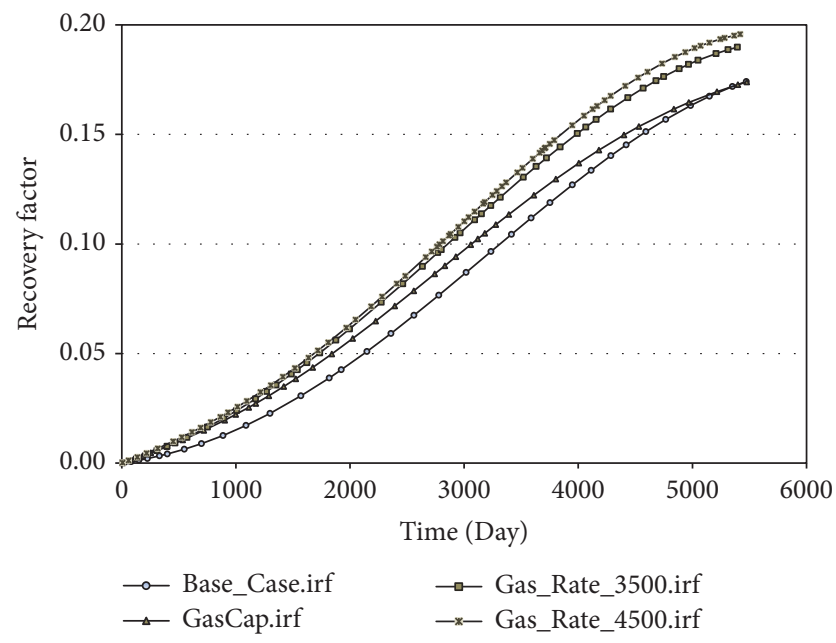

FIGURE 13: Effect of initial gas cap and gas injection rate $\left(Q_{\text {solvent }}=\right.$ $3,500 \mathrm{~m}^{3} /$ day and $Q_{\text {solvent }}=4,500 \mathrm{~m}^{3} /$ day) on the recovery of SWVapex after 15 years of production.

Gas Cap. To investigate the effect of the presence of a small gas cap a simulation model was created by adjusting a gas zone with $3 \mathrm{~m}$ height. Although the simulation results reveal the same ultimate recovery in comparison with the reference case, a higher recovery factor can be achieved in earlier time. This suggests that the existence of a small gas cap is favorable for the process. It is believed that, in such a situation, injected solvent can be distributed over a wider oil interface and

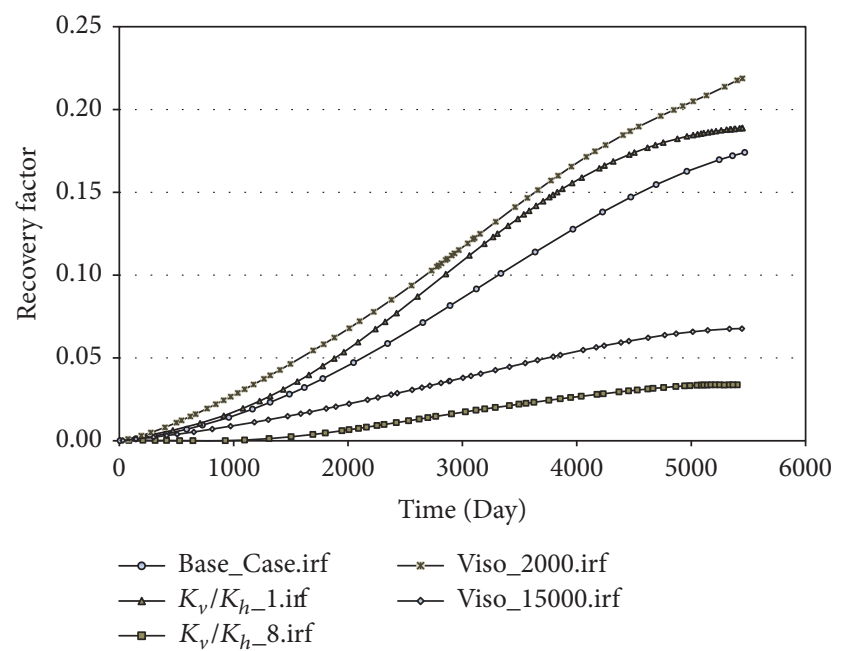

FIGURE 14: Effect of permeability anisotropy $\left(K_{h} / K_{v}=1\right.$ and $K_{h} / K_{v}$ $=8)$ and crude oil viscosity $\left(\mu_{\text {oil }}=15000 \mathrm{cp}\right.$ and $\left.\mu_{\text {oil }}=2000 \mathrm{cp}\right)$ on ultimate oil recovery after 15 years.

improves the mass transfer rate between solvent and in situ fluid.

Permeability Anisotropy. The original permeability is set to 1,500 and $750 \mathrm{md}$ in horizontal and vertical directions, respectively. To analyze the effect of permeability anisotropy, two additional models were constructed with horizontal to vertical permeability ratio of $K_{h} / K_{v}=1$ and 8 . The 


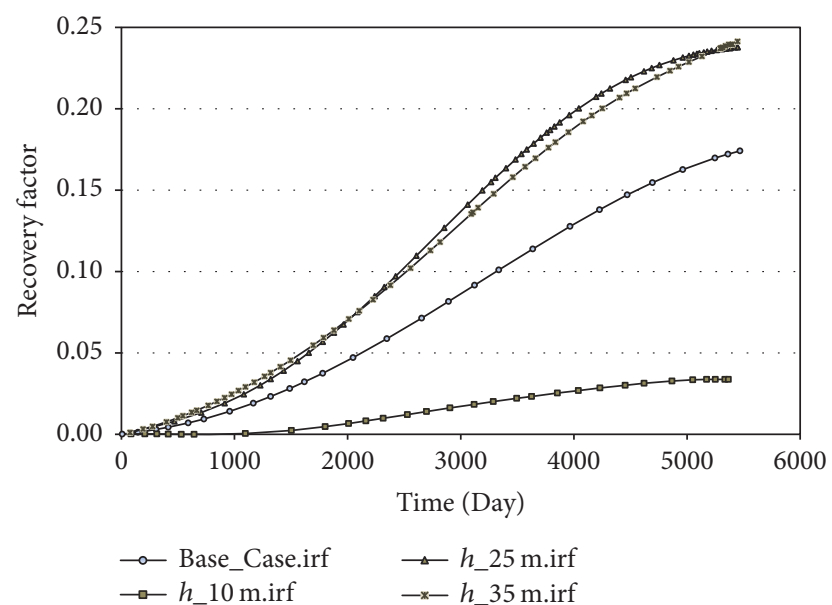

FIGURE 15: Effect of reservoir thicknesses $(10,19.6,25$, and $35 \mathrm{~m})$ on ultimate oil recovery after 15 years.

value of horizontal permeability was kept constant, and the vertical permeability has been changed. Figure 14 displays that decreasing of the vertical permeability causes difficulty in the vertical propagation of the hydrocarbon solvent and also hinders the oil drainage toward production. Larger permeability anisotropy is an unfavorable reservoir condition and decreases total oil recovery.

Viscosity and Reservoir Height. Fluid properties were altered to examine the effect of viscosity. Two alternative viscosities of 2,000 and 15,000 cp at reservoir temperature were chosen. The results show that the application of SW-Vapex in extra viscous oils is a challenging issue. Initial viscosity greater than $15,000 \mathrm{cp}$ delays the drainage process and prevents the proper growth of the solvent chamber. This can be counterbalanced by more solvent consumption which is not economically viable. The same conclusion can be drawn for the effect of the reservoir thickness. Thin reservoirs cast a shadow over the gravity effect. A vapor chamber of considerable height must be developed for efficient oil drainage. Thin reservoirs with a height of $10 \mathrm{~m}$ or less are not good candidates for application of SW-Vapex. However, an increase of the height over 25 meters does not offer significant improvement. Figure 15 compares the cumulative oil recovery for three different reservoir thicknesses of 10, 25, and $35 \mathrm{~m}$.

\section{Discussion}

Early time study indicated that applying vapor extraction process alone with single well configuration loses its viability due to inherent slow nature of the solvent. In this point, implementation of an optimization scenario can play a crucial role in the improvement of the oil recovery. By comparing the results of different scenarios, it was found that steam cycling was the most efficient method. The objective of early time heat treatment is to heat the reservoir, as much as possible, in a uniform manner to provide an initial cavity in the formation. It is worth mentioning that selection of early time strategy is fully dependent on reservoir property and operating conditions of the Vapex process and may differ from case to case.

Heavy oil viscosity has a pronounced effect on the success of SW-Vapex. Due to related difficulties in the mobilization of the crude oil with a viscosity greater than $15,000 \mathrm{cp}$, these highly viscous reservoirs may need to use other production methods. The same conclusion can be drawn for the height of the reservoir. A minimum height should exist to allow proper development of the vapor chamber in the vertical direction. For a reservoir with height that is less than 4 meters, the ultimate recovery would not exceed $5 \%$ of the STOOIP. Since the practical hydrocarbon solvents used in the operation are almost expensive, the solvent requirement and consumption are the key economic factor for the Vapex recovery. An optimum value should be specified to obtain minimum solvent to oil ratio. As expected the vertical permeability value plays the major role in the rate of vertical propagation of the vapor chamber. Since the diluted oil should be drained toward the producer and the solvent substitutes that, the vertical permeability reduction could reduce the oil recovery. Therefore, the presence of the shale layers in the reservoir is expected to make the process more challenging.

\section{Conclusions}

This study aimed at screening of applicability of single well Vapex process through numerical modeling.

(1) A sound analogy for simulation study of single well Vapex process has been developed to simulate both wellbore and reservoir sections.

(2) Preheating treatment is a must for creating initial proper voidage in the reservoir to enhance vapor propagation. Preheating has a significant effect on the total oil recovery in the long run. Cyclic steaming with two periods of soak and production in 180 days was selected as an efficient preheating scenario to heat the near wellbore area uniformly.

(3) Solvent injection rate should be adjusted to achieve maximum oil production rate by consuming minimum solvent. Higher injection rates just shorten the breakthrough time and leave the oil unaffected.

(4) Application of SW-Vapex in reservoirs with a reservoir thickness approximately less than $10 \mathrm{~m}$ and initial oil viscosity more than $1,500 \mathrm{cp}$ seems to be not feasible. The presence of a relatively small gas cap aids the solvent diffusion by increasing the contact surface area.

\section{Nomenclature}

CWE: Cold water equivalent

ES-SAGD: Expanding solvent steam assisted gravity drainage

HCS: $\quad$ Hydrocarbon solvent

$K_{h}: \quad$ Horizontal permeability

$K_{v}: \quad$ Vertical permeability 
md: $\quad$ Millidarcy

Mpa: Megapascal

SAGD: Steam assisted gravity drainage

SOR: $\quad$ Steam oil ratio

STOOIP: Stock tank original oil in place

SW: $\quad$ Single well

VAPEX: Vapor extraction

cp: $\quad$ Centipoise

$\mu$ : Viscosity.

\section{Competing Interests}

The authors declare that they have no competing interests.

\section{References}

[1] R. M. Butler and I. J. Mokrys, "Recovery of heavy oils using vapourized hydrocarbon solvents: further development of the vapex process," Journal of Canadian Petroleum Technology, vol. 32, no. 6, 2013.

[2] R. F. Meyer, E. D. Attanasi, and P. A. Freeman, Heavy oil and natural bitumen resources in geological basins of the world (No. 2007-1084), 2007.

[3] R. M. Butler and Q. Jiang, "Improved recovery of heavy oil by Vapex with widely spaced horizontal injectors and producers," Journal of Canadian Petroleum Technology, vol. 39, no. 1, pp. 48$56,2000$.

[4] J. Yazdani and B. B. Maini, "New experimental model design for VAPEX process experiments," in Proceedings of the Paper Presented at the Canadian International Petroleum Conference. Petroleum Society of Canada, PETSOC-2004-263, Calgary, Canada, June 2004.

[5] A. Yazdani and B. Maini, "The effective diffusion/dispersion coefficient in vapor extraction of heavy oil," Petroleum Science and Technology, vol. 27, no. 8, pp. 817-835, 2009.

[6] A. Yazdani and B. B. Maini, "Modeling of the VAPEX process in a very large physical model," Energy and Fuels, vol. 22, no. 1, pp. 535-544, 2008.

[7] N. Rezaei, O. Mohammadzadeh, L. A. James, and I. Chatzis, "Experimental investigation of the VAPEX process in vuggy porous media," SPE Journal, vol. 19, no. 1, pp. 101-108, 2014.

[8] F. Torabi, B. Y. Jamaloei, B. M. Stengler, and D. E. Jackson, “The evaluation of $\mathrm{CO}_{2}$-based vapour extraction (VAPEX) process for heavy-oil recovery," Journal of Petroleum Exploration and Production Technology, vol. 2, no. 2, pp. 93-105, 2012.

[9] M. Mohammadpoor and F. Torabi, "Comprehensive experimental study and numerical simulation of vapour extraction (VAPEX) process in heavy oil systems," The Canadian Journal of Chemical Engineering, vol. 93, no. 11, pp. 1929-1940, 2015.

[10] M. Mohammadpoor, Q. Firouz, A. Reza, and F. Torabi, "Implementing simulation and artificial intelligence tools to optimize the performance of the $\mathrm{CO}_{2}$ sequestration in coalbed methane reservoirs," in Proceedings of the Paper Presented at the Carbon Management Technology Conference. Carbon Management Technology Conference, January 2012.

[11] G. Hocking, T. W. Cavender, and J. Person, "Single-well SAGD: overcoming permeable lean zones and barriers," in Proceedings of the Canadian Unconventional Resources Conference, January 2011.

[12] G. Hocking, T. W. Cavender, and J. Person, "Unimpaired performance of single-well SAGD in variable geology," in Proceedings of the Gas \& Oil Expo \& Conference, pp. 11-13, Calgary, Canada, June 2011.

[13] X. Deng, H. Huang, L. Zhao, D. H.-S. Law, and T. N. Nasr, "Simulating the ES-SAGD process with solvent mixture in Athabasca reservoirs," Journal of Canadian Petroleum Technology, vol. 49, no. 1, pp. 38-46, 2010.

[14] M. D. McMILLAN, Determining reserves in low permeability and layered reservoirs using the minimum terminal decline rate method: how good are the predictions? [Ph.D. dissertation], Texas A\&M University, 2011.

[15] E. S. Adewole, "Factors that affect pressure distribution of horizontal wells in a layered reservoir with simultaneous gas cap and bottom water drive," Journal of Petroleum and Gas Engineering, vol. 6, no. 1, pp. 1-9, 2015.

[16] M. Li, H. Chen, Y. Zhang, W. Li, Y. Wang, and M. Yu, "A coupled reservoir/wellbore model to simulate the steam injection performance of horizontal wells," Energy Technology, vol. 3, no. 5, pp. 535-542, 2015.

[17] S. Huang, C. Huang, L. Cheng, T. Liu, Z. Chen, and W. Mao, "Experiment investigation of steam flooding of horizontal wells for thin and heterogeneous heavy oil reservoira," in Proceedings of the SPE Latin American and Caribbean Petroleum Engineering Conference, Quito, Ecuador, 2015.

[18] A. J. Yazdani and B. B. Maini, "Effect of drainage height and grain size on production rates in the vapex process: Experimental Study," SPE Reservoir Evaluation and Engineering, vol. 8, no. 3, pp. 205-213, 2005.

[19] H. Rahnema, R. Kharrat, and B. Rostami, "Experimental and numerical study of vapor extraction process (VAPEX) in heavy oil fractured reservoir," in Proceedings of the Paper Presented at the Canadian International Petroleum Conference, Petroleum Society of Canada, Calgary, Canada, June 2008.

[20] D. Ji, M. Dong, and Z. Chen, "Analysis of steam-solventbitumen phase behavior and solvent mass transfer for improving the performance of the ES-SAGD process," Journal of Petroleum Science and Engineering, vol. 133, pp. 826-837, 2015.

[21] F. Fang and T. Babadagli, "Three dimensional visualization of solvent chamber growth during the VAPEX processes: an experimental approach using laser," Journal of Petroleum Science and Engineering, vol. 142, pp. 46-67, 2016.

[22] M. M. Al-Hadhrami, A. S. Alkindi, and A. H. Muggeridge, "Experimental and numerical investigations into the effect of heterogeneities on the recovery of heavy oil by VAPour EXtraction (VAPEX)," Fuel, vol. 135, pp. 413-426, 2014.

[23] J. Shi and J. Y. Leung, "Physics-based proxy for vapex process modeling in heterogeneous reservoirs," in Proceedings of the SPE Heavy Oil Conference Canada 2013, pp. 2223-2241, Alberta, Canada, June 2013.

[24] B. Shabani, E. Kazemzadeh, A. Entezari, J. Aladaghloo, and S. Mohammadi, "The calculation of oil-water relative permeability from capillary pressure data in an oil-wet porous media: case study in a dolomite reservoir," Petroleum Science and Technology, vol. 32, no. 1, pp. 38-50, 2014.

[25] J. E. Nenniger and S. G. Dunn, "How fast is solvent based gravity drainage?" in Proceedings of the Canadian International Petroleum Conference, Petroleum Society of Canada, January 2008.

[26] J. E. Nenniger and L. Gunnewiek, "Dew point vs bubble point: a misunderstood constraint on gravity drainage processes," in Proceedings of the Canadian International Petroleum Conference, Petroleum Society of Canada, January 2009. 
[27] L. Zhao, "Steam alternating solvent process," in Proceedings of the Paper Presented at the SPE International Thermal Operations and Heavy Oil Symposium and Western Regional Meeting, Bakersfield, Calif, USA, March 2004.

[28] T. N. Nasr, G. Beaulieu, H. Golbeck, and G. Heck, "Novel expanding solvent-SAGD process 'ES-SAGD', Journal of Canadian Petroleum Technology, vol. 42, no. 1, pp. 13-16, 2003.

[29] T. N. Nasr and O. R. Ayodele, "Thermal techniques for the recovery of heavy oil and bitumen," in Proceedings of the SPE International Improved Oil Recovery Conference in Asia Pacific, Kuala Lumpur, Malaysia, December 2005.

[30] T. N. Nasr and O. R. Ayodele, "New hybrid steam-solvent processes for the recovery of heavy oil and bitumen," in Proceedings of the 12th Abu Dhabi International Petroleum Exhibition and Conference (ADIPEC '06), pp. 791-807, November 2006.

[31] O. R. Ayodele, T. N. Nasr, G. Beaulieu, and G. Heck, "Laboratory experimental testing and development of an efficient low pressure ES-SAGD process," Journal of Canadian Petroleum Technology, vol. 48, no. 9, pp. 54-61, 2009.

[32] J. J. Ivory, R. Zheng, T. N. Nasr, X. Deng, G. Beaulieu, and G. Heck, "Investigation of low pressure ES-SAGD," in Proceedings of the International Thermal Operations and Heavy Oil Symposium, Calgary, Canada, October 2008.

[33] M. Keshavarz, R. Okuno, and T. Babadagli, "Efficient oil displacement near the chamber edge in ES-SAGD," Journal of Petroleum Science and Engineering, vol. 118, pp. 99-113, 2014.

[34] J. You, H. Rahnema, and M. D. McMillan, "Numerical modeling of unsteady-state wellbore heat transmission," Journal of Natural Gas Science and Engineering, vol. 34, pp. 1062-1076, 2016.

[35] A. Memarzadeh and H. Rahnema, "Thermodynamic analysis of solvent assisted steam injection," in Proceedings of the SPE Annual Technical Conference and Exhibition, SPE, Houston, Tex, USA, September 2015.

[36] H. Rahnema, M. Barrufet, and D. Mamora, "Experimental study of air injection in SAGD chamber," in Proceedings of the Canadian Unconventional Resources Conference, Calgary, Canada, November 2011.

[37] M. Keshavarz, R. Okuno, and T. Babadagli, "Optimal application conditions for steam/solvent coinjection," SPE Reservoir Evaluation \& Engineering, vol. 18, no. 1, pp. 20-38, 2015.

[38] K. T. Elliot and A. R. Kovscek, "A numerical analysis of the single-well steam assisted gravity drainage process (SWSAGD)," Petroleum Science and Technology, vol. 19, no. 7-8, pp. 733-760, 2001.

[39] S. Akin and S. Bagci, "A laboratory of single-well steam-assisted gravity drainage process," Journal of Petroleum Science and Engineering, vol. 32, no. 1, pp. 23-33, 2001.

[40] B. Rostami, S. Etminan, A. Soleimani, and R. Kharrat, "Effect of capillarity and surface tension on the performance of VAPEX process," in Proceedings of the Canadian International Petroleum Conference, Calgary, Alberta, 2007.

[41] H. Rahnema, S. M. Ghaderi, and S. Farahani, "Simulation of VAPEX process in problematic reservoirs: a promising tool along with experimental study," in Proceedings of the SPE/EAGE Reservoir Characterization and Simulation Conference, Society of Petroleum Engineers, Abu Dhabi, UAE, October 2007.

[42] W. Li, D. D. Mamora, and Y. Li, "Light-and heavy-solvent impacts on solvent-aided-SAGD process: A Low-Pressure Experimental Study," Journal of Canadian Petroleum Technology, vol. 50, no. 4, pp. 19-30, 2011.
[43] H. Shin and M. Polikar, "Review of reservoir parameters to optimize SAGD and fast-SAGD operating conditions," Journal of Canadian Petroleum Technology, vol. 46, no. 1, pp. 35-41, 2007.

[44] S. A. Gherabati, R. G. Hughes, H. Zhang, and C. D. White, "A large scale network model to obtain interwell formation characteristics," in Proceedings of the SPE Western Regional Meeting, Bakersfield, Calif, USA, March 2012.

[45] S. M. A. Gherabati, B. Dabir, and A. Hesami, "Well included flowbased grid generation for heterogeneous reservoirs," in Proceedings of the SPE Annual Technical Conference and Exhibition, Denver, Colo, USA, September 2008.

[46] F. Ahmadloo, K. Asghari, A. Henni, and N. Freitag, "Capillarity and drainage height effects on the diffusion/dispersion coefficient in the VAPEX process," Energy Sources, Part A: Recovery, Utilization and Environmental Effects, vol. 36, no. 3, pp. 323-335, 2014.

[47] H. Abukhalifeh, S. R. Upreti, and A. Lohi, "Effect of drainage height on concentration-dependent propane dispersion in vapex," The Canadian Journal of Chemical Engineering, vol. 90, no. 2, pp. 336-341, 2012.

[48] F. Fang and T. Babadagli, "Diffusion and dispersion dominated solvent injection processes in oil saturated porous media: 3D visualization experiments using laser technology," in Proceedings of the SPE Annual Technical Conference and Exhibition (ATCE '14), pp. 932-948, October 2014.

[49] M. Alfi and J. Park, "Theoretical analysis of the local orientation effect and the lift-hyperlayer mode of rodlike particles in fieldflow fractionation," Journal of Separation Science, vol. 37, no. 7, pp. 876-883, 2014.

[50] M. Alfi, H. Nasrabadi, and D. Banerjee, "Experimental investigation of confinement effect on phase behavior of hexane, heptane and octane using lab-on-a-chip technology," Fluid Phase Equilibria, vol. 423, pp. 25-33, 2016.

[51] P. Ebrahimi and P. Jaiswal, "Enhancement of sub-basalt stratigraphy of Fareo-Shetland Basin using directional-filter," in Proceedings of the SEG Technical Program Expanded Abstracts, pp. 1570-1574, Society of Exploration Geophysicists, Denver, Colo, USA, 2014.

[52] M. D. McMillan, H. Rahnema, J. Romiluy, and F. J. Kitty, "Effect of exposure time and crude oil composition on low-salinity water flooding," Fuel, vol. 185, pp. 263-272, 2016.

[53] M. D. McMillan, C. R. Nwachukwu, and H. Rahnema, "Geospatial analysis of compositional variations across the eagle ford and barnett shale plays," in Proceedings of the SPE Annual Technical Conference and Exhibition, SPE, Dubai, UAE, September 2016. 


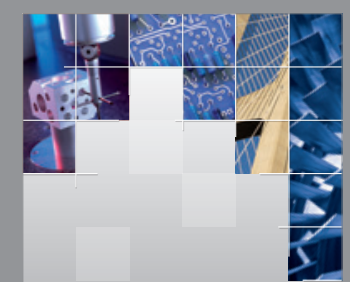

\section{Enfincering}
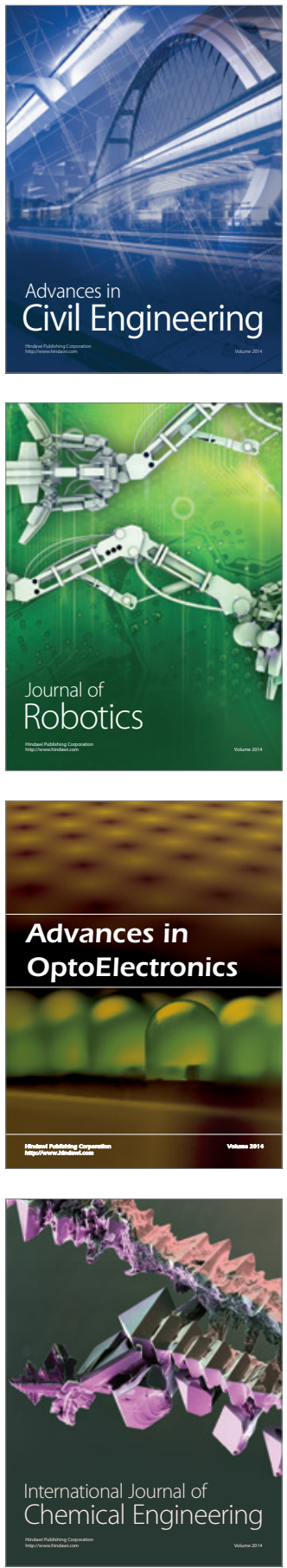

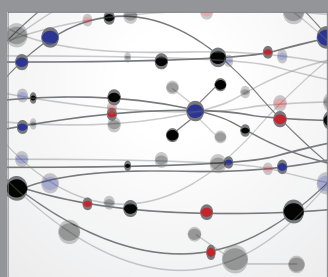

The Scientific World Journal

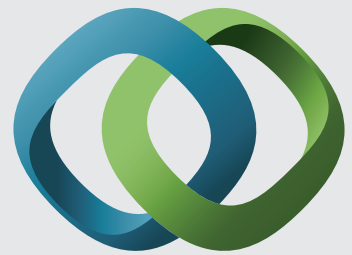

\section{Hindawi}

Submit your manuscripts at

http://www.hindawi.com
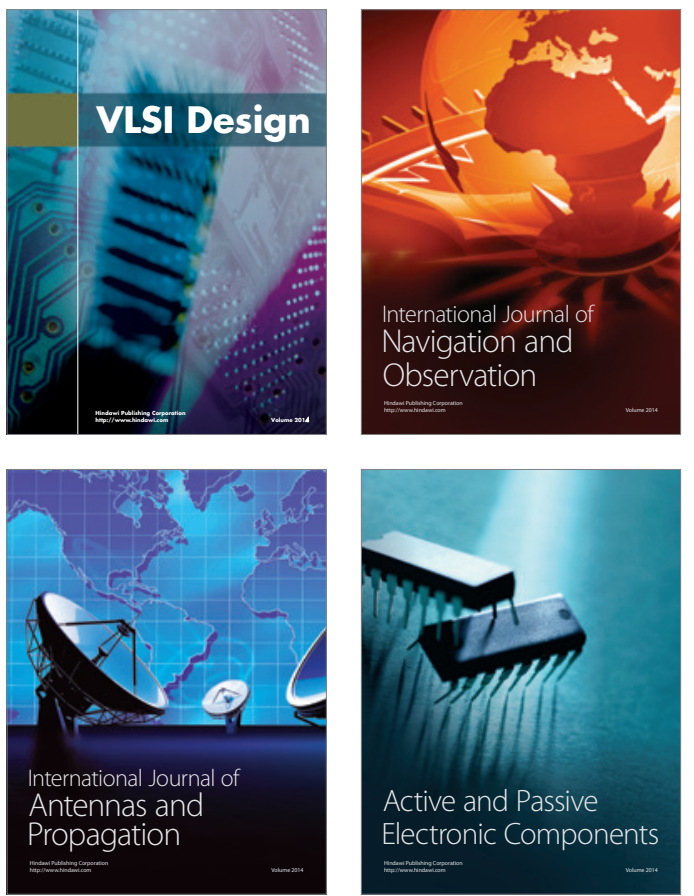
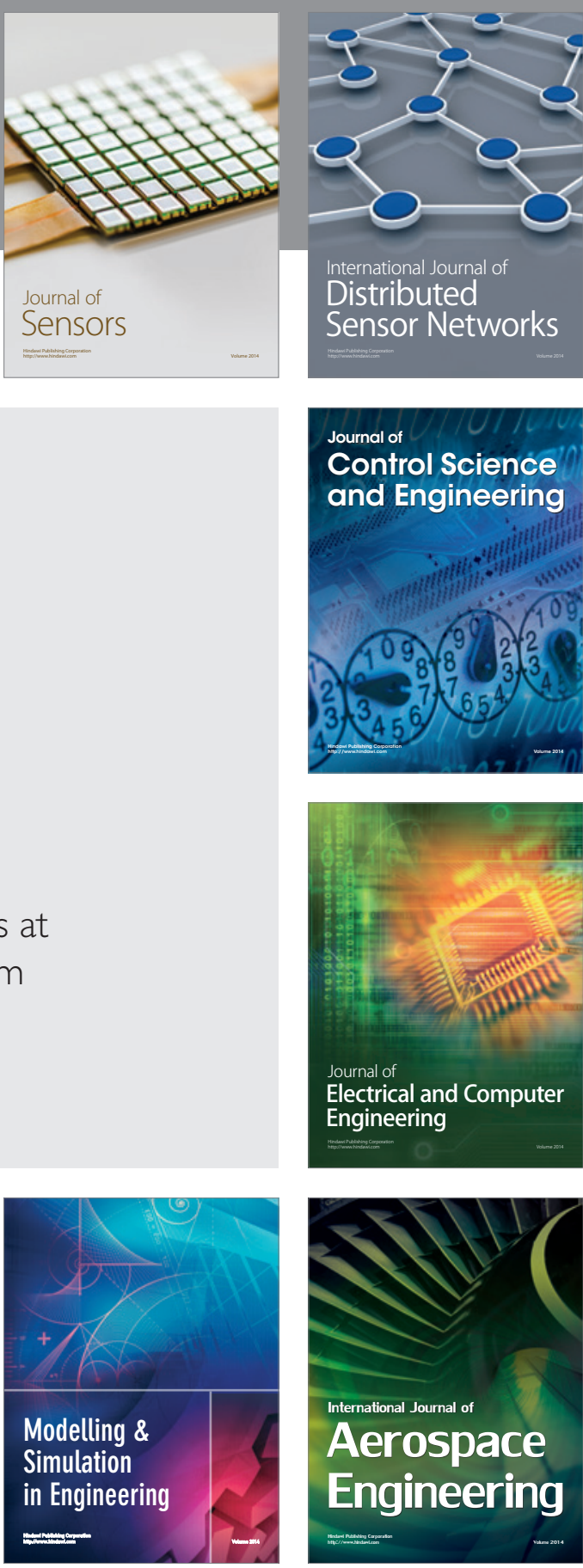

International Journal of

Distributed

Sensor Networks

Journal of

Control Science

and Engineering
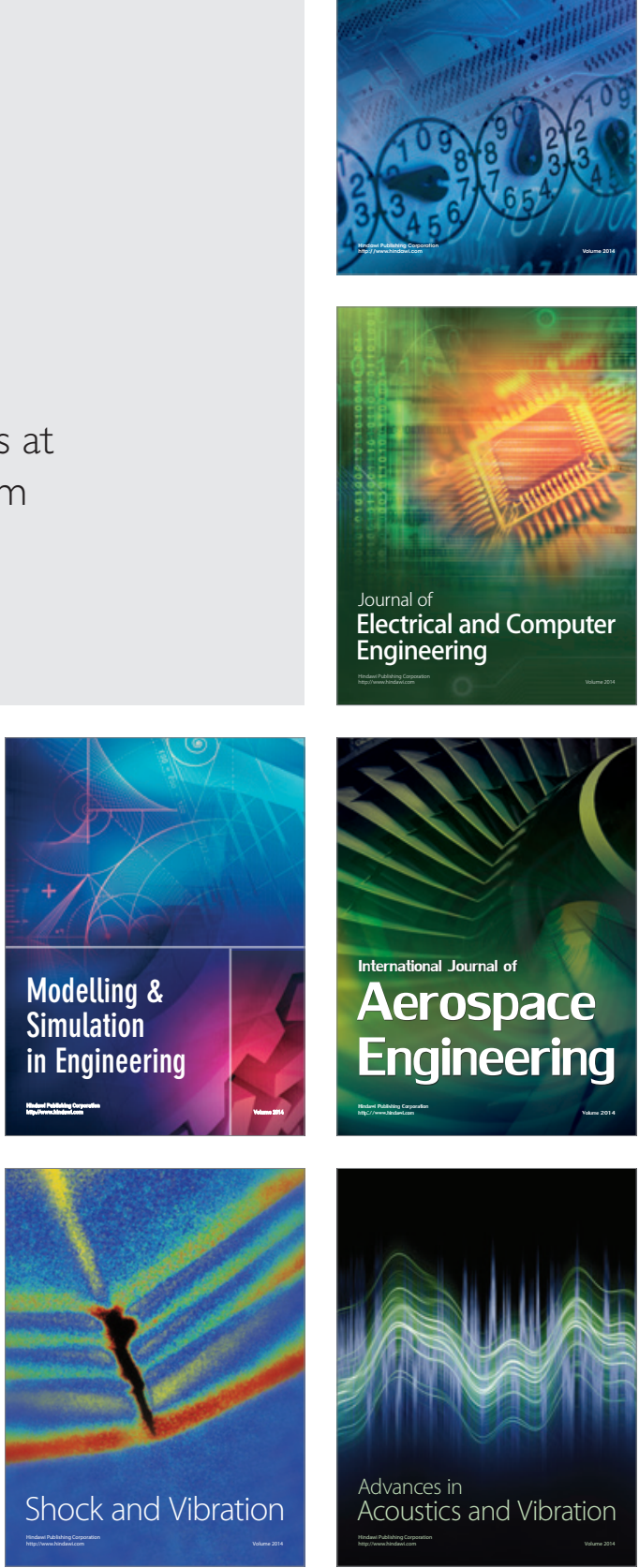